\title{
GENDER DIFFERENCES IN OUTCOME FOLLOWING PRIMARY PERCUTANEOUS CORONARY INTERVENTION
}

\author{
Sunitha Viswanathan'1, Satheesan Praveen ${ }^{2}$, Anup Kumar Sadanadan ${ }^{3}$ \\ 1 Professor, Department of Cardiology, Government Medical College, Trivandrum. \\ ${ }^{2}$ Assistant Professor, Department of Cardiology, Government Medical College, Trivandrum. \\ ${ }^{3}$ Consultant Cardiologist, Department of Cardiology, SUT Hospital, Trivandrum.
}

\section{BACKGROUND}

ABSTRACT

Women with ST elevation myocardial infarction had poor outcomes in prior fibrinolytic trials. We examined the impact of female gender on in-hospital as well as intermediate outcomes of primary PCI patients in a tertiary care centre.

\section{MATERIALS AND METHODS}

From January 2011 to December 2012, 576 consecutive patients undergoing primary PCI at a tertiary referral centre were included in a descriptive study. Clinical information was prospectively collected onto a database at the time of the procedure. Inhospital, 30-day and 6-month follow-up data were collected by review of records during review in OPD and through telephonic contact. Data was analysed with PSPP open source.

\section{RESULTS}

Female patients (16\%) were (3 years) older than males. Females had higher incidences of diabetes (51\% vs. 40\%), systemic hypertension (56\% vs. $38 \%$ ) and dyslipidaemia (88\% vs. 83\%). Both anterior wall MI and inferior wall MI were equally represented in the study population, but more females were in cardiogenic shock (5.43\% vs. 2.27\%). Adjunctive medical treatment including GP IIb/IIIa blocker use was higher in men. The in-hospital incidence of MACE (10 (10.87\%) vs. 29 (5.99\%), p=0.087) and death $(9(9.78 \%)$ vs. $25(5.17 \%)$ p= 0.062) did not differ significantly between women and men. But there was a trend toward increased in-hospital mortality and MACE in women. The cumulative MACE events $(11.96 \%$ vs. $6.2 \%)$ and mortality $(10.87 \%$ vs. $5.37 \%$ ) at six months was significantly more in women.

\section{CONCLUSION}

In this study, female gender did not emerge as an independent predictor for in-hospital MACE and mortality, but had higher MACE at six months follow-up.

\section{KEYWORDS}

Women, Myocardial Infarction, Coronary Disease, Percutaneous Coronary Intervention.

HOW TO CITE THIS ARTICLE: Viswanathan S, Praveen S, Sadanadan AK. Gender differences in outcome following primary percutaneous coronary intervention. J. Evolution Med. Dent. Sci. 2018;7(05):578-584, DOI: 10.14260/jemds/2018/132

\section{BACKGROUND}

Coronary artery disease (CAD) is the leading cause of death worldwide regardless of the sex. CAD makes up more than half of all cardiovascular events in males and females $<75$ years of age and approximately every 40 seconds an American will have an MI. ${ }^{1}$ Women's awareness that CVD is their leading cause of death has increased substantially from 1997 to 2012. For coronary heart disease in specific, mortality rates have fallen for both men and women over this time period, but much more rapidly in men than women. This decline was because of influence of evidence-based medicine and reduction in several risk factors. The 1 year as well as 5 years mortality and morbidity are higher for females as compared to males after an MI. Thus, understanding even minor variations between men and women in development

'Financial or Other Competing Interest': None.

Submission 26-12-2017, Peer Review 15-01-2018,

Acceptance 18-01-2018, Published 29-01-2018.

Corresponding Author:

Dr. Satheesan Praveen,

Assistant Professor,

Department of Cardiology,

Government Medical College,

Trivandrum- 695011.

E-mail: praveensatheesan@gmail.com

DOI: $10.14260 /$ jemds $/ 2018 / 132$

\section{(c) (i) $(5)$}

or progression of cardiovascular disease, use of evidencebased therapies and response to therapy is paramount.

Primary percutaneous coronary intervention ( $\mathrm{pPCI}$ ) has clearly proven its superiority over thrombolytic therapy in terms of immediate restoration of normal coronary flow in the infarct related artery as well as a reduction in recurrent ischaemia or reinfarction.2,3 Women with acute myocardial infarction (AMI) are at increased risk for death compared with men, irrespective of reperfusion modality. ${ }^{4-10}$ Whether there are fundamental differences between women and men in mortality after MI or whether such observed differences reflect corresponding differences in baseline characteristics has long been a topic of discussion.

The present study aims to assess impact of gender on outcomes like major adverse cardiac events (composite of death, MI and ischaemia driven target vessel revascularisation), death, stroke, reinfarction, stent thrombosis and major bleeding in a series of consecutive patients with acute myocardial infarction treated with primary PCI.

\section{MATERIALS AND METHODS}

This is a retrospective descriptive study with intermediate term follow-up of consecutive patients with acute myocardial infarction admitted to Government Medical College, 
Trivandrum who underwent primary PCI from January 2011 to December 2012.

All patients who presented with acute ST elevation myocardial infarction within 12 hours of onset of symptoms and underwent primary PCI and given consent were included in the study. Detailed history, physical, electrocardiographic, echocardiographic examination and laboratory examination results were collected retrospectively by systematic review of old records. Haemodynamically stable patients as well as patients with cardiogenic shock were included. STEMI management was carried out according to the AHA/ACC2009 guidelines. ${ }^{11}$ In-hospital, 30 -day and 6-month follow-up data were collected by review of records during review in OPD and through telephonic contact.

The main outcome measure was major adverse cardiac events defined as composite of death, reinfarction and ischaemic target vessel revascularisation. Other outcomes of interest were mortality, individual components of MACE and stroke. Diagnosis of reinfarction was made on the basis of typical chest pain, new ST segment changes and an increase in serum creatinine value of at least $50 \%$ over previous trough level in at least two samples. The diagnosis of stroke required confirmation by CT or MRI imaging of head. After discharge assessment of clinical status was made by means of telephonic contact and during review in outpatient department at 30 days and 6 months. Stent thrombosis was defined by the ARC criteria. ${ }^{12}$

All subjects underwent a routine battery of investigations including haemogram, electrocardiograph, renal function tests and liver function tests at the time of admission in ICCU. Each and every patient underwent an echocardiogram soon after stabilising clinically. The exclusion criteria for the study was ST elevation MI in the territory of target vessel, in which previous PCI with or without stenting was done and patients who were not willing to participate in the study. Every consecutive patient fulfilling the inclusion criteria and exclusion criteria was included in the sample after obtaining an informed consent either from the patient or from the nearest of kin if the patient was not in a condition to give consent.

The data thus collected was assessed during the period of index hospitalisation at 30 days and at 6 months for (1) Major Adverse Cardiac Events (MACE)- composite of death, MI and ischaemia driven target vessel revascularisation, (2). Death, (3) Stroke, (4) Stent thrombosis and (5) Major bleeding. The protocol was cleared by the Institutional Ethical Committee. The database used for data collection was Microsoft Access. Data was analysed with PSPP (Open Source). The graphs have been prepared with Microsoft Excel. Chi-square test was used for comparison of categorical variables. Student's ' $t$ ' test was used for comparison between means. Survival analysis was done using Kaplan-Meier curves for in-hospital mortality. The log-rank test was used to determine whether the difference in survival was significant.

\section{RESULTS}

A total of 584 patients were admitted with a diagnosis of ST elevation myocardial infarction. Ninety two females $(15.97 \%)$ and 484 males (84.03\%) presenting with STEMI and undergoing PCI were included (Figure 1).

\begin{tabular}{|c|c|c|}
\hline Characteristic & Mean & $\begin{array}{l}\text { Standard } \\
\text { Deviation }\end{array}$ \\
\hline Age (yrs.) & 56.22 & 11.288 \\
\hline $\begin{array}{l}\text { Total Ischaemic Period } \\
\text { (mins) }\end{array}$ & 290.76 & 129.440 \\
\hline $\begin{array}{l}\text { Door to Balloon Time } \\
\text { (mins) }\end{array}$ & 87.88 & 46.81 \\
\hline ST Resolution (\%) & 61.08 & 23.232 \\
\hline Ejection Fraction (\%) & 50.22 & 9.954 \\
\hline Total Cholesterol (mg/dL) & 217.88 & 45.186 \\
\hline LDL (mg/dL) & 141.65 & 43.275 \\
\hline HDL (mg/dL) & 46.90 & 12.738 \\
\hline Triglycerides (mg/dL) & 137.18 & 68.260 \\
\hline Total Stent Length (mm) & 21.09 & 8.883 \\
\hline Mean Stent Diameter $(\mathrm{mm})$ & 3.110 & 0.408 \\
\hline \multicolumn{3}{|c|}{$\begin{array}{c}\text { Table I. Baseline Characteristics of the Study Cohort } \\
\text { Continuous Variables }\end{array}$} \\
\hline
\end{tabular}

\begin{tabular}{|c|c|c|c|}
\hline Characteristics & Groups & Number & Percentage \\
\hline Age & $18-50$ yrs. & 177 & $30.73 \%$ \\
\hline & $51-70$ yrs. & 341 & $59.20 \%$ \\
\hline >70 yrs. & 57 & $9.9 \%$ \\
\hline Mender & Male & 484 & $84.03 \%$ \\
\hline DM & & 92 & $15.97 \%$ \\
\hline Hypertension & & 239 & $41.49 \%$ \\
\hline $\begin{array}{c}\text { Dyslipidaemia } \\
\text { Premature CAD }\end{array}$ & & 484 & $40.97 \%$ \\
\hline Smoking & & 60 & $10.42 \%$ \\
\hline Past h/o ACS & & 338 & $58.76 \%$ \\
\hline Previous PCI & & 3 & $7.5 \%$ \\
\hline Previous CVA & & 17 & $0.52 \%$ \\
\hline $\begin{array}{c}\text { Type of } \\
\text { Myocardial } \\
\text { Infarction }\end{array}$ & AWMI & 287 & $49.82 \%$ \\
\hline $\begin{array}{c}\text { Contrast } \\
\text { Nephropathy }\end{array}$ & IWMI & 289 & $50.17 \%$ \\
\hline Table & 12 & $2.08 \%$ \\
\hline
\end{tabular}

Table II. Baseline Characteristics of the Study PopulationCategorical Variables

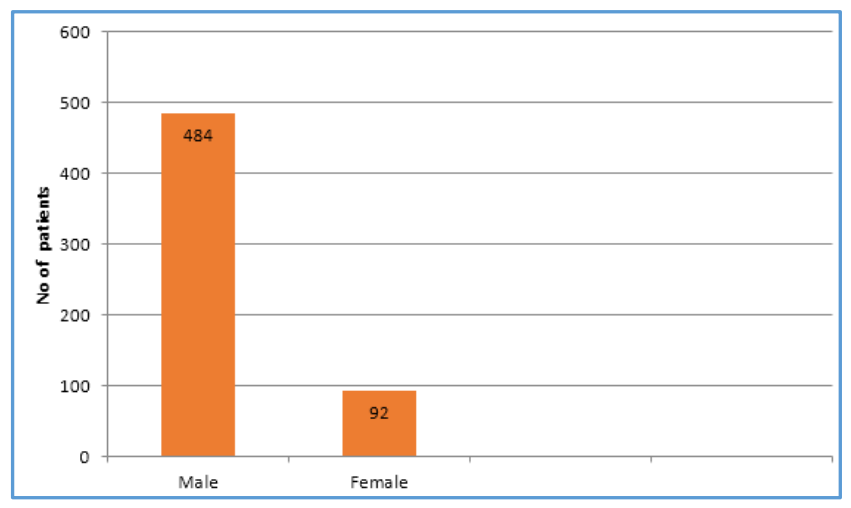

Figure 1. Figure showing Gender Distribution of the Study Population

Men had undergone a previous angioplasty more often than females, but the medical history concerning prior myocardial infarction did not differ between groups (Table II). There was a moderate but statistically significant difference in mean age (women: 58.82 years, men: 55.73 
years, $\mathrm{p}=0.016$ ) (Table III). There was no difference in total ischaemic period (307.63 minutes vs. 287.57 minutes, $\mathrm{p}=0.175$ ) or door-to-balloon time ( 87 vs. $88.05, \mathrm{p}=0.846$ ) between men and women (Table III). Both anterior and inferior infarctions were equally represented in the study cohort (Table IV). Systemic hypertension (52 (56\%) vs. 184 $(38 \%) \mathrm{p}=0.001)$ and Diabetes mellitus ( 47 (51.09\%) vs. 192 $(39.6 \%) \mathrm{p}=0.05)$ were more commonly found in women (Table IV). The distribution of family history of premature CAD and presence of dyslipidaemia were comparable between the two groups. The rate of patients with cardiogenic shock was similar in both groups (11 $(2.27 \%)$ vs. $5(5.43 \%), p=0.091)$ as was the distribution of Killip class at admission (Table IV).

\begin{tabular}{|c|c|c|c|}
\hline Characteristics & $\begin{array}{c}\text { Male } \\
\text { Mean (SD) }\end{array}$ & $\begin{array}{c}\text { Female } \\
\text { Mean (SD) }\end{array}$ & $\begin{array}{c}\text { P value } \\
\text { (Independent } \\
\text { Samples Test) }\end{array}$ \\
\hline Age (yrs.) & $\begin{array}{c}55.73 \\
(12.02)\end{array}$ & $\begin{array}{c}58.82 \\
(22.62)\end{array}$ & 0.016 \\
\hline $\begin{array}{l}\text { Total Ischaemic } \\
\text { Period (mins) }\end{array}$ & $\begin{array}{c}287.57 \\
(115.96)\end{array}$ & $\begin{array}{c}307.63 \\
(254.55)\end{array}$ & 0.175 \\
\hline $\begin{array}{l}\text { Door-to-Balloon } \\
\text { Time (mins) }\end{array}$ & $\begin{array}{c}88.05 \\
(32.52) \\
\end{array}$ & $\begin{array}{c}87 \\
(100.40) \\
\end{array}$ & 0.846 \\
\hline $\begin{array}{c}\text { ST Resolution } \\
(\%)\end{array}$ & $\begin{array}{c}61.22 \\
(24.04) \\
\end{array}$ & $\begin{array}{c}60.33 \\
(21.21) \\
\end{array}$ & 0.730 \\
\hline $\begin{array}{c}\text { Ejection Fraction } \\
(\%)\end{array}$ & $\begin{array}{l}50.25 \\
(7.07)\end{array}$ & $\begin{array}{l}50.06 \\
(1.41)\end{array}$ & 0.867 \\
\hline $\begin{array}{c}\text { Total Cholesterol } \\
\text { (mg \%) }\end{array}$ & $\begin{array}{l}215.36 \\
(62.93)\end{array}$ & $\begin{array}{c}231.42 \\
(111.72)\end{array}$ & 0.003 \\
\hline LDL (mg \%) & $\begin{array}{l}139.28 \\
(43.13) \\
\end{array}$ & $\begin{array}{l}154.38 \\
(65.05) \\
\end{array}$ & 0.003 \\
\hline HDL (mg \%) & $\begin{array}{c}46.3 \\
(11.31)\end{array}$ & $\begin{array}{c}50.15 \\
(44.54)\end{array}$ & 0.010 \\
\hline $\begin{array}{l}\text { Triglycerides } \\
\text { (mg \%) }\end{array}$ & $\begin{array}{c}139 \\
(13.43)\end{array}$ & $\begin{array}{c}126 \\
(12.02)\end{array}$ & 0.120 \\
\hline $\begin{array}{l}\text { Mean Stent Length } \\
(\mathrm{mm})\end{array}$ & $\begin{array}{c}21.20 \\
(11.31)\end{array}$ & $\begin{array}{l}20.48 \\
(1.41)\end{array}$ & 0.495 \\
\hline $\begin{array}{c}\text { Mean Stent } \\
\text { Diameter }(\mathrm{mm})\end{array}$ & $\begin{array}{l}3.1158 \\
(0.35) \\
\end{array}$ & $\begin{array}{l}3.1355 \\
(0.35) \\
\end{array}$ & 0.686 \\
\hline \multicolumn{4}{|c|}{$\begin{array}{c}\text { Table III. Comparing the Study Characteristics } \\
\text { between the Two Gender Groups }\end{array}$} \\
\hline
\end{tabular}

\begin{tabular}{|c|c|c|c|}
\hline Characteristics & $\begin{array}{c}\text { Male } \\
\text { N (\%) }\end{array}$ & $\begin{array}{c}\text { Female } \\
\text { N (\%) }\end{array}$ & P value \\
\hline DM & $192(39.6)$ & 47 (51.09) & 0.050 \\
\hline Hypertension & $184(38 \%)$ & 52 (56\%) & 0.001 \\
\hline Dyslipidaemia & $403(83.26 \%)$ & $81(88 \%)$ & 0.28 \\
\hline Smoking & 335 (69\%) & 0 & 0.000 \\
\hline Family h/o CAD & $48(9.9 \%)$ & $12(13.04 \%)$ & 0.355 \\
\hline Past h/o ACS & $37(7.64 \%)$ & $6(6.52 \%)$ & 0.831 \\
\hline Previous PCI & $3(0.62 \%)$ & 0 & 0.448 \\
\hline AWMI & $243(51.24 \%)$ & $44(47.83 \%)$ & 0.702 \\
\hline IWMI & $117(24.17 \%)$ & $23(25 \%)$ & 0.865 \\
\hline IWMI + RVMI & $124(25.62 \%)$ & $25(27.17 \%)$ & 0.755 \\
\hline Killip Class I & $372(76.86 \%)$ & $71(77.1 \%)$ & 0.947 \\
\hline Killip Class II & $80(16.53 \%)$ & $12(13.04 \%)$ & 0.402 \\
\hline Killip Class III & $21(4.43 \%)$ & $4(4.34 \%)$ & 0.996 \\
\hline Killip Class IV & $11(2.27 \%)$ & $5(5.43 \%)$ & 0.091 \\
\hline \multicolumn{4}{|c|}{ Table IV. Table Comparing the Major Risk Factors } \\
\hline
\end{tabular}

Angiographic Characteristics and Procedural Outcomes AWMI and IWMI were equally represented between men and women. There was no difference between men and women in the allocation of the target vessel to LAD and RCA, the incidence of 1, 2 or 3 vessel disease and baseline TIMI flow between the two groups (Table V). LCx as target vessel was more common in men compared to women. The rate of administration of GP IIb/IIIa inhibitors was statistically significant. Difference between the genders with more male patients receiving the same drug (male 292 (60.33\%) vs. female $44(47.83 \%) \mathrm{p}=0.029)$, but there was no significant difference in the rate of administration of bivalirudin between the two groups in a small number of patients who received the same drug (Figure 2). There was no difference between men and women with regard to femoral artery as access site for PCI $(77.18 \%$ vs. $83.7 \%, p=0.147)$, whereas more male patients underwent PCI via radial route $(99(20 \%)$ vs. $10(10.87 \%), p=0.031$ ) (Table V). The procedural details such as mean stent length (male ( 21.20 vs. $20.48, p=0.495)$ ) mean stent diameter (male (3.1158 vs. female, $p=0.686)$ ) were not different between the two groups, but women had a smaller reference luminal diameter at baseline (male (3.337 vs. $3.238, p=0.037)$ ). A higher number of male patients received bare metal stents $(289(59.71 \%)$ vs. 42 (45.65\%), $\mathrm{p}=0.012$ ), whereas the number of patients who had received drug eluting stents and netted BMS stent was not significantly different between the two groups (Figure 2). Significantly, greater proportion of female patients underwent POBA (12 $(13.04 \%)$ vs. $30(6.19 \%) p=0.028))$, whereas greater proportion of male patients underwent thrombus aspiration (48 (9.91\%) vs. 3 (3.26\%), p= 0.044). There was no significant difference between two groups with regard to staged PCI and IABP support.

\begin{tabular}{|c|c|c|c|}
\hline Characteristics & $\begin{array}{c}\text { Male } \\
\text { N (\%) }\end{array}$ & $\begin{array}{l}\text { Female } \\
\mathrm{N}(\%)\end{array}$ & $P$ value \\
\hline $\begin{array}{l}\text { Route for PCI- } \\
\text { Femoral }\end{array}$ & $372(77.18 \%)$ & 77 (83.7\%) & 0.147 \\
\hline $\begin{array}{l}\text { Route for PCI- } \\
\text { Radial }\end{array}$ & $99(20 \%)$ & $10(10.87 \%)$ & 0.031 \\
\hline $\begin{array}{l}\text { Single Vessel } \\
\text { Disease }\end{array}$ & $276(57.02 \%)$ & $55(59.78 \%)$ & 0.623 \\
\hline $\begin{array}{l}\text { Two Vessel } \\
\text { Disease }\end{array}$ & $149(30.78 \%)$ & 27 (29.35\%) & 0.783 \\
\hline $\begin{array}{l}\text { Three Vessel } \\
\text { Disease }\end{array}$ & $59(12.2 \%)$ & $10(10.87 \%)$ & 0.720 \\
\hline \multicolumn{4}{|l|}{ Culprit Vessel } \\
\hline RCA & $199(41.12 \%)$ & 4245.66\%) & 0.418 \\
\hline LCX & $46(9.5 \%)$ & $3(3.26 \%)$ & 0.049 \\
\hline LAD & $240(49.59 \%)$ & $46(50 \%)$ & 0.942 \\
\hline $\begin{array}{c}\text { Reference Vessel } \\
\text { Diameter [mean } \\
(\mathrm{SD})]\end{array}$ & $3.337(0)$ & $3.238(0.70)$ & 0.037 \\
\hline \multicolumn{4}{|c|}{ Baseline TIMI Flow } \\
\hline TIMI $0-1$ & $417(86.16 \%)$ & $73(79.35 \%)$ & 0.092 \\
\hline TIMI 2 & $30(61.98 \%)$ & $7(7.61 \%)$ & 0.613 \\
\hline TIMI 3 & $29(5.99 \%)$ & $99(9.97 \%)$ & 0.179 \\
\hline \multicolumn{4}{|c|}{$\begin{array}{c}\text { Table V. Table comparing the Angiographic } \\
\text { Details of the Two Group }\end{array}$} \\
\hline
\end{tabular}




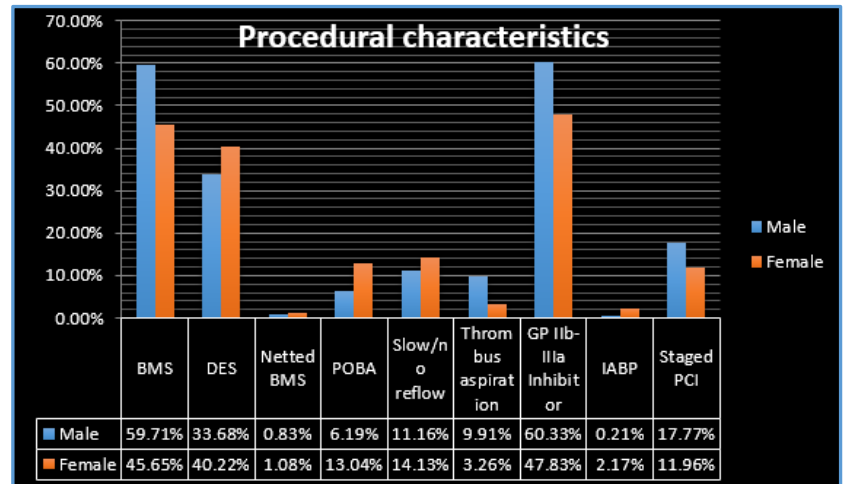

Figure 2. Figure showing the Procedural Characteristics during PCI between Men and Women

The rate of post-interventional major bleeding complications including intracranial haemorrhage $(1.09 \%$ vs. $1.0, p=0.962)$ ), contrast nephropathy ( 3 vs. $9, p=0.388$ ), arteriovenous fistula ( 0 vs. $1, p=0.660$ ) dissecting aneurysm of femoral artery ( 0 vs. $1, p=0.660$ ) stent embolisation ( 0 vs. $1, p=0.660)$, acute arterial occlusion of femoral artery (0 vs. $1, p=0.660)$ and haemopericardium ( 0 vs. $3, p=0.449)$ did not differ significantly between females and males (Table VI).

\begin{tabular}{|c|c|c|c|}
\hline Characteristics & $\begin{array}{l}\text { Male } \\
\text { N (\%) }\end{array}$ & $\begin{array}{l}\text { Female } \\
\text { N (\%) }\end{array}$ & P value \\
\hline $\begin{array}{c}\text { Moderate-to-Severe } \\
\text { Bleeding } \\
\text { (Gastrointestinal + } \\
\text { Intracranial Bleed) }\end{array}$ & $5(1.03 \%)$ & $1(1.08 \%)$ & 0.962 \\
\hline Contrast Nephropathy & $9(1.86 \%)$ & $3(3.26 \%)$ & 0.388 \\
\hline Thrombocytopenia & $5(1.03 \%)$ & 0 & 0.328 \\
\hline CVA & $2(0.41 \%)$ & $1(1.08 \%)$ & 0.448 \\
\hline Haemopericardium & $3(0.62 \%)$ & 0 & 0.449 \\
\hline AV Fistula & $1(0.21 \%)$ & 0 & 0.660 \\
\hline Stent Embolisation & $1(0.21 \%)$ & 0 & 0.660 \\
\hline $\begin{array}{c}\text { Dissecting Aneurysm } \\
\text { of Femoral Artery }\end{array}$ & $1(0.21 \%)$ & 0 & 0.660 \\
\hline $\begin{array}{l}\text { Acute Femoral Arterial } \\
\text { Occlusion }\end{array}$ & $1(0.21 \%)$ & 0 & 0.660 \\
\hline \multicolumn{4}{|c|}{$\begin{array}{c}\text { Table VI. Table comparing the Procedural Complications } \\
\text { of the Study Group }\end{array}$} \\
\hline
\end{tabular}

\section{Clinical Outcome}

The in-hospital incidence of MACE (10 (10.87\%) vs. 29 (5.99\%), p= 0.087) and death (9 (9.78\%) vs. $25(5.17 \%)$ $\mathrm{p}=0.062$ ) did not differ significantly between women and men (Table VII). But there was a trend toward increased inhospital mortality and MACE in women. Most of the MACE events are due to in-hospital death (females 9 (9.78\%) vs. males 25 (5.17\%), p=0.062)) in both the groups. Rest of the MACE events are contributed by stent thrombosis with ischaemia driven target vessel revascularisation. There was no significant difference in the incidence of stroke (female (1) vs. males (2), $p=0.448$ ) between females and males. The cumulative MACE events and mortality at six months was significantly more in women (Figure 4). A subgroup of diabetic men and women were analysed to assess the impact of gender difference in mortality. But the subgroup analysis failed to show any gender difference in mortality on account of diabetes.
There was no significant gender differences in the prescription of medications like antiplatelets aspirin $(98.47 \%$ vs. $94.38 \%, p=0.501)$, Clopidogrel $(92.81 \%$ vs. $95.5 \%$, $\mathrm{p}=0.282$ ), Prasugrel ( $3.92 \%$ vs. $3.61 \%, \mathrm{p}=0.893$ ), Ticagrelor $(0.43 \%$ vs. $1.2 \%, p=0.384)$, statin $(95.86 \%$ vs. $95.18 \%$, $\mathrm{p}=0.777)$ or beta-blocker $(81.91 \%$ vs. $80.72 \%, \mathrm{p}=0.795)$ between the two groups, whereas there was a male preponderance in the prescription of ACEI (88.24\% vs. $79.52 \%, p=0.030$ ) (Figure 3).

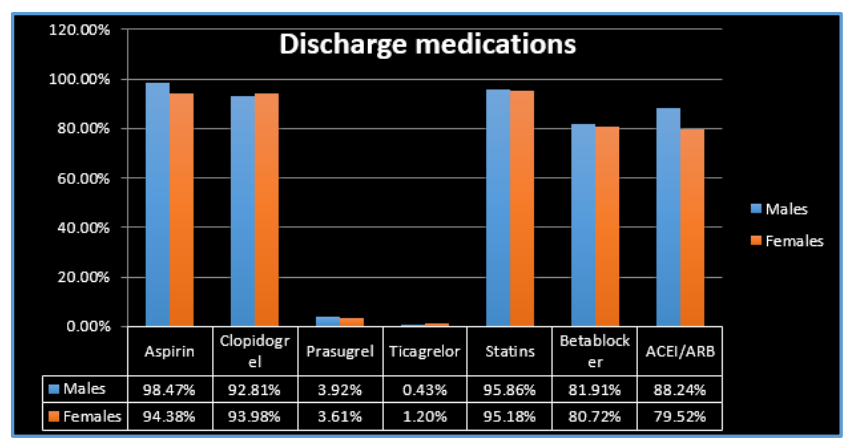

Figure 3. Discharge Medications of the Study Group

\begin{tabular}{|c|c|c|c|}
\hline Characteristic & $\begin{array}{l}\text { Male } \\
\text { N (\%) }\end{array}$ & $\begin{array}{c}\text { Female } \\
\text { N (\%) }\end{array}$ & P value \\
\hline In-Hospital MACE & $29(5.99 \%)$ & $10(10.87)$ & 0.087 \\
\hline MACE 30 days & $30(6.2 \%)$ & $10(10.87 \%)$ & 0.106 \\
\hline MACE 6 Months & $30(6.2 \%)$ & $11(11.96 \%)$ & 0.048 \\
\hline Death In-Hospital & $25(5.17 \%)$ & $9(9.78 \%)$ & 0.062 \\
\hline Death 30 days & $26(5.37 \%)$ & $9(9.78 \%)$ & 0.104 \\
\hline Death 6 months & $26(5.37 \%)$ & $10(10.87 \%)$ & 0.045 \\
\hline Reinfarction In-Hospital & $4(0.87 \%)$ & $1(1.2 \%)$ & 0.772 \\
\hline Reinfarction 30 days & $5(1.09 \%)$ & 0 & 0.973 \\
\hline Reinfarction 6 months & $6(1.31 \%)$ & 0 & 0.294 \\
\hline $\begin{array}{c}\text { Ischaemic TVR In- } \\
\text { Hospital }\end{array}$ & $4(0.87 \%)$ & 0 & 0.392 \\
\hline Ischaemic TVR 30 days & $5(1.09 \%)$ & 0 & 0.339 \\
\hline Ischaemic TVR 6 months & $8(1.74 \%)$ & 0 & 0.225 \\
\hline $\begin{array}{c}\text { Stent Thrombosis In- } \\
\text { Hospital }\end{array}$ & $4(0.87 \%)$ & 1 & 0.772 \\
\hline $\begin{array}{c}\text { Stent Thrombosis } 30 \\
\text { days } \\
\end{array}$ & $5(1.09 \%)$ & 0 & 0.973 \\
\hline $\begin{array}{c}\text { Stent Thrombosis } 6 \\
\text { months }\end{array}$ & $6(1.31 \%)$ & 0 & 0.394 \\
\hline Stroke In-hospital & $4(0.87 \%)$ & 0 & 0.393 \\
\hline $\begin{array}{c}\text { In-Hospital Cardiac } \\
\text { Failure }\end{array}$ & $46(10.02 \%)$ & $12(13.04 \%)$ & 0.228 \\
\hline
\end{tabular}

\section{Patients with MACE}

At univariate analyses, patients developing MACE had higher incidence of diabetes mellitus, dyslipidaemia and family history of premature CAD (Table VIII). There was no significant difference in medical history regarding cardiogenic shock, previous history of acute coronary syndrome and previous history of percutaneous intervention. There was also no difference in total ischaemic period or door-to-balloon time. But the percentage of ST resolution and ejection fraction were low in patients who developed MACE. 


\begin{tabular}{|c|c|c|c|}
\hline Characteristics & With MACE & $\begin{array}{l}\text { Without } \\
\text { MACE }\end{array}$ & $P$ value \\
\hline Age in yrs. [mean (SD)] & $59.55(8.48)$ & $55.99(12.02)$ & 0.11 \\
\hline Females [N (\%)] & $10(10.8 \%)$ & $82(89.1 \%)$ & 0.064 \\
\hline \multicolumn{4}{|l|}{ Risk Factors } \\
\hline $\begin{array}{c}\text { Diabetes Mellitus } \\
{[\mathrm{N}(\%)]}\end{array}$ & $23(9.6 \%)$ & $216(90.37 \%)$ & 0.01 \\
\hline Hypertension [N (\%)] & $18(7$ & $218(92.3 \%)$ & 0.254 \\
\hline $\begin{array}{l}\text { Family h/o CAD } \\
{[\mathrm{N}(\%)]}\end{array}$ & $23(38.3 \%)$ & $37(61.7 \%)$ & 0.000 \\
\hline $\begin{array}{c}\text { Cardiogenic Shock } \\
{[\mathrm{N}(\%)]}\end{array}$ & $7(43.7 \%)$ & $9(56.2 \%)$ & NS \\
\hline Previous ACS [N (\%)] & $1(2.3 \%)$ & $42(97.7 \%)$ & 0.203 \\
\hline Previous PCI [N (\%)] & 0 & $3(100 \%)$ & NS \\
\hline $\begin{array}{l}\text { TIP Minutes } \\
\text { [mean (SD)] }\end{array}$ & $\begin{array}{l}315.11 \\
(14.14) \\
\end{array}$ & $\begin{array}{c}289.7 \\
(115.96) \\
\end{array}$ & 0.289 \\
\hline $\begin{array}{l}\text { DBT Minutes } \\
{[\text { mean }(\mathrm{SD})]}\end{array}$ & $\begin{array}{c}79.94 \\
(31.81) \\
\end{array}$ & $\begin{array}{c}88.41 \\
(33.51) \\
\end{array}$ & 0.158 \\
\hline $\begin{array}{l}\text { ST Resolution (\%) } \\
{[\text { mean (SD)] }}\end{array}$ & $\begin{array}{c}49 \\
(43.84) \\
\end{array}$ & $\begin{array}{c}61.62 \\
(24.04) \\
\end{array}$ & 0.019 \\
\hline EF (\%) [mean (SD)] & 42.89 (18.38) & $50.71(7.01)$ & 0.000 \\
\hline \multicolumn{4}{|c|}{$\begin{array}{c}\text { Table VIII. Table comparing Patients with MACE and } \\
\text { without MACE with Respect to Major Risk Factors and } \\
\text { Procedural Outcomes }\end{array}$} \\
\hline
\end{tabular}

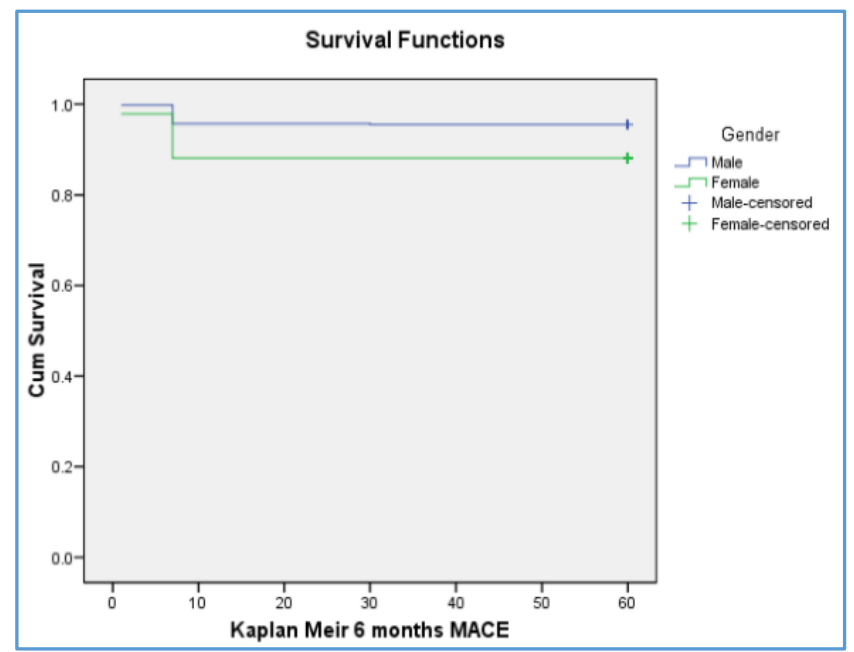

Figure 4. Kaplan-Meier Survival Curves according to Gender

Kaplan-Meier analysis estimates the rates of MACE during in-hospital days and intermediate term follow-up. Rates of death between women and men were significantly different during the intermediate term follow-up ( $p=0.004$, log rank test).

\section{DISCUSSION}

The present descriptive study analysed the clinical presentation and outcomes of women and men presented with STEMI to our centre during a two-year period. To avoid bias no selection criteria were applied regarding demographic characteristics, clinical status at presentation and time interval from the onset of symptoms.

\section{Baseline Characteristics of the Study Population}

There was a small but statistically significant difference in mean age between women and men (58.82 years vs. 55.73 years, $p=0.016$ ). It has been shown that because of the protective effects of oestrogen until the menopause, women tend to be older than men at the time of presentation with
CVD. In the AMIS plus registry ${ }^{13}$ of 20,290 patients of ACS (STEMI and NSTEMI) average age of women was 70 years and in the study of gender and myocardial salvage after reperfusion treatment for acute MI by J Mehelli et al, ${ }^{14}$ it was 72 years. But in the BARI 2D15 trial of men and women randomised to aggressive medical treatment alone or aggressive medical treatment with prompt revascularisation, the mean age of men and women were $62 \mathrm{yrs}$. In the present study, women were younger than their western counterparts. Diabetes mellitus (47 (51.09\%) vs. 192 (39.6\%), $\mathrm{p}=0.05)$ and systemic hypertension (52 (56\%) vs. 184 (38\%), p= 0.001) was more common in women. The distribution of family history of premature CAD and presence of dyslipidaemia were comparable between the two groups. But women had more severe dyslipidaemia and the absolute values of total cholesterol, LDL and triglycerides were higher in women, but the absolute value of HDL cholesterol was higher in men.

The distribution of major risk factors in the current study are similar with that of the distribution of risk factors in the APEX-AMI trial. ${ }^{16}$ Of 199,690 patients with ACS who underwent PCI in the ACC-NCDR PCI ${ }^{17}$ registry in both ACS categories (UA/NSTEMI vs. STEMI), women were older and had a higher incidence of diabetes (insulin or non-insulin dependent) and hypertension. In the APEX-MI trial, women had longer median time from symptom onset to PCI (3.6 hrs. vs. $3.3 \mathrm{hrs}$.), but similar door to PCI time (1.1 hr.). In the present study, there was no significant difference in the total ischaemic period (307.63 minutes vs. 287.57 minutes, $\mathrm{p}=0.175$ ) or door to balloon time between the gender indicating that there is no bias in treatment between the genders. This is an important finding since the time to primary $\mathrm{PCI}$ is strongly associated with mortality risk.

\section{Angiographic and Procedural Characteristics}

In the present study, women had a smaller reference luminal diameter at baseline (male 3.337 vs. $3.238, p=0.037$ ) and significantly greater proportion of female patients underwent POBA $((13.04 \%)$ vs. $(6.19 \%), p=0.028)$, but stent length (male 21.20 vs. 20.48), $\mathrm{p}=0.495$ ) and stent diameter (male 3.1158 vs. female, $p=0.686$ ) were the same between genders. But the mean stent diameter in women was 3.238 indicating that women has good sized vessel in contrast to many other studies. Even though greater proportion of female patients underwent POBA, there was no difference in the vessel diameter between two genders. The higher proportion of POBA in female patients is accounted for by the fact that some of these female patients died immediately after balloon dilatation before they could be stented.

In the present study, a higher number of male patients received bare metal stents $(59.71 \%$ vs. $5.65 \%, p=0.012)$ whereas the number of patients received drug eluting stents and netted BMS stent was not significantly different between the two groups. Compared with bare metal stent (BMS) implantation, studies of both the sirolimus eluting and paclitaxel-eluting stent demonstrated similar results in both men and women in reducing restenosis, target vessel revascularisation (TVR) and major adverse cardiac events (MACE) at 1-year follow-up. This occurred despite the fact that women tended to be older and have more comorbidities, such as diabetes and hypertension. DES's seem to be similarly efficacious in women and men, though it must be remembered that because women often make up a 
minority of the patients enrolled. Studies are underpowered to effectively evaluate the results in this subgroup.

The rate of administration of GP IIb/IIIa inhibitors showed significant difference between the genders with more male patients receiving the same drug (male 292 (60.33\%) vs. female 44 (47.83\%), $\mathrm{p}=0.029)$. In the BMC $2^{18}$ registry, a quality-controlled multicentre registry of contemporary PCI, also Glycoprotein (GP) IIb/IIIa inhibitors were used less commonly in women. Previous data has suggested that the greatest benefit from GP IIb/IIIa inhibitors is derived by patients presenting at high risk (elevated troponin levels). Further, it has been reported that in patients with cardiogenic shock, the benefit of GP IIb/IIIa inhibitors persists through long-term follow-up. In general, patients with ACS display increased platelet activation and increased levels of inflammatory mediators, both correlating with the degree of myocardial damage. GP IIb/IIIa inhibitors suppress platelet aggregation and have anti-inflammatory effects. Both mechanisms contribute to the beneficial effects of GP IIb/IIIa inhibitors in ACS. In their study, Stefan Kralev et al ${ }^{19}$ has suggested that GP IIb/IIIa inhibitors might have mitigated gender-related differences in the vascular risk factor profile of their patient cohort.

\section{Clinical Outcomes}

The pooled mortality of the study cohort was $5.9 \%$. The inhospital mortality in women $(9.78 \%)$ and men $(5.17 \%)$, $\mathrm{p}=0.087$ ) was not significantly different between men and women. The cumulative mortality and MACE at 30 days was also not different between men and women. At six months, there was significant difference in mortality $26(5.37 \%)$ vs. $10(10.87 \%), p=0.045$ and MACE 30 (6.2\%) vs. 11 (11.96\%), $\mathrm{p}=0.048$ ) in women. But in the subgroup analysis of diabetic patients, there was no significant difference in mortality between men and women. There was no difference in the occurrence of reinfarction, ischaemia driven TVR or incidence of stroke between men and women.

Studies comparing outcomes of men and women with ACS have provided conflicting results and unconvincing explanations. In the New York angioplasty registry, ${ }^{20}$ the inhospital mortality for all primary angioplasty patients between 1993 and 1996 was 5.81\% overall, but 9.04\% in women. In some studies, female gender was a risk factor for long-term mortality among patients who underwent primary angioplasty but not for short-term mortality, whereas in other studies mortality was higher for women soon after PCI and before hospital discharge, mainly because of a higher rate of non-cardiac death. De Luca et $\mathrm{al}^{21}$ explained the higher mortality rate in women by the smaller reference luminal diameter and the higher prevalence of cardiovascular risk factors in women, a difference in presentation which has been confirmed by many other studies. The APEX AMI trial also found a consistently smaller reference luminal diameter and a higher cardiovascular risk profile in women. The smaller target vessel size is associated with an increased risk of restenosis, but does not appear to be a predictor for mortality. ${ }^{22}$ In this study though there was a significant difference in reference vessel diameter between men and women, the mean reference vessel diameter of female cohort was $3.28 \mathrm{~mm}$. The problem of a worse outcome in women undergoing PCI has been underscored for a long time. There is a lack of prospective studies specifically designed to evaluate the outcome of PCI or specific strategies for PCI in women. Several studies of patients undergoing coronary revascularisation have reported a difference in outcome between men and women with the conclusion in some that procedures in female patients are associated with more adverse events. However, the reasons for the outcome of differences seen in some publications are likely to be multifactorial. Largely because of the protective effects of oestrogen until the menopause, women tend to be 10 years older than men at the time of presentation with CVD. In addition, they may present with more extensive disease as the diagnosis of coronary disease may be considerably delayed. Female patients tend to have smaller, more tortuous coronary vessels and thus the frequency of stent implantation may be lower. However, the significant improvements in angioplasty techniques, and in particular the introduction of drug-eluting stents (DES) and smaller size stents has helped to overcome these issues. In TAMIS ${ }^{23}$ (conducted in 1995 1997), stenting was not a common therapeutic strategy for AMI (one-fourth vs. two-thirds for TAMIS and TAMIS II, respectively). Comparing in-hospital mortality between TAMIS and TAMIS-II, women have a similar in-hospital mortality rate to that of men after AMI. In the present study, severity of CAD and the frequency of stent implantation was also not different.

\section{Procedural Complications}

In patients presenting with ACS, advanced age, female sex, history of bleeding and renal insufficiency are independently associated with a higher risk of bleeding. In this study, the incidence of major bleeding complications did not differ between women and men. The incidence of vascular complications was also very less in the overall study cohort and there was no gender difference in the incidence of vascular complications.

The main findings of the study indicate that women with acute MI treated with primary PCI had in-hospital outcome similar to that of men, despite their higher age and adverse risk factor profile at presentation. Though the study showed a non-significant trend towards higher in-hospital mortality in women, together with the findings of study by J Mehelli et al suggests that in general women with STEMI benefit from primary PCI to at least same degree as men. These findings combined with the fact that thrombolysed female patients have higher in-hospital mortality than men, a strong recommendation can be made for primary PCI in women presenting with STEMI, but higher MACE and mortality at six months in women emphasises the need for a more extensive therapeutic strategy.

\section{CONCLUSION}

In this study, female gender did not emerge as an independent predictor for in-hospital MACE and mortality. Primary PCI may improve the chances of survival of women, despite their more adverse cardiovascular profile. Door-toballoon time and total ischaemic period was similar between two genders indicating that women in Kerala have good social and family support system. The similar vessel size, procedural success and similar stent length between genders indicates that there is no significant difference in the complexity of lesion. But higher MACE at six months in 
women emphasises the need for a more extensive therapeutic strategy.

\section{REFERENCES}

[1] Benjamin EJ, Blaha MJ, Chiuve SE, et al. Heart disease and stroke statistics-2017 update. A report from the American Heart Association. Circulation 2017;135(10):e146-e603.

[2] Grines C, Patel A, Zijlstra F, et al. Primary coronary angioplasty compared with intravenous thrombolytic therapy for acute myocardial infarction: six-month follow up and analysis of individual patient data from randomized trials. Am Heart J 2003;145(1):47-57.

[3] Keely EC, Boura JA, Grines CL. Primary angioplasty versus intravenous thrombolytic therapy for acute myocardial infarction: a quantitative review of 23 randomised trials. Lancet 2003;361(9351):13-20.

[4] Weaver WD, White HD, Wilcox RG, et al. Comparisons of characteristics and outcomes among women and men with acute myocardial infarction treated with thrombolytic therapy. GUSTO-I investigators. JAMA 1996;275(10):777-82.

[5] Malacrida R, Genoni M, Maggioni AP, et al. A comparison of the early outcome of acute myocardial infarction in women and men. The Third International Study of Infarct Survival Collaborative Group. N Engl J Med 1998;338(1):8-14.

[6] Vaccarino V, Berkman LF, Krumholz HM. Long-term outcome of myocardial infarction in women and men: a population perspective. Am J Epidemiol 2000;152(10):965-73.

[7] Watanabe CT, Maynard C, Ritchie JL. Comparison of short-term outcomes following coronary artery stenting in men versus women. Am J Cardiol 2001;88(8):848-52.

[8] Stone GW, Grines CL, Browne KF, et al. Comparison of in-hospital outcomes in men and women treated by either thrombolytic therapy or primary coronary angioplasty for acute myocardial infarction. Am J Cardiol 1995;75(15):987-92.

[9] Tamis-Holland JE, Palazzo A, Stebbins AL, et al. Benefits of direct angioplasty for women and men with acute myocardial infarction: results of the Global Use of Strategies to Open Occluded Arteries in Acute Coronary Syndromes Angioplasty (GUSTO II-B) Angioplasty Substudy. Am Heart J 2004;147(1):133-9.

[10] Zijlstra F, Hoorntje JC, de Boer MJ, et al. Long-term benefit of primary angioplasty as compared with thrombolytic therapy for acute myocardial infarction. N Engl J Med 1999;341(99):1413-9.

[11] Kushner FG, Hand M, Smith SC, et al. 2009 focused updates: ACC/aha guidelines for the management of patients with ST-elevation myocardial infarction. A report of the American College of Cardiology Foundation/American Heart Association Task Force on Practice Guidelines. Circulation 2009;120 (22):2271-306.
[12] Cutlip DE, Windecker S, Mehran R, et al. Clinical end points in coronary stent trials: a case for standardized definitions. Circulation 2007;115(17):2344-51.

[13] Radovanovic D, Erne P, Urban P, et al. Gender differences in management and outcomes in patients with acute coronary syndromes: results on 20,290 patients from the AMIS Plus Registry. Heart 2007;93(11):1369-75.

[14] Mehilli J, Ndrepepa G, Kastrati A, et al. Gender and myocardial salvage after reperfusion treatment in acute myocardial infarction. JACC 2005;45(6):828-31.

[15] Tamis-Holland JE, Lu J, Korytkowski M, et al. Sex differences in presentation and outcome among patients with type 2 diabetes and coronary artery disease treated with contemporary medical therapy with or without prompt revascularization: a report from the BARI 2D Trial (Bypass Angioplasty Revascularization Investigation 2 Diabetes). J Am Coll Cardiol 2013;61(17):1767-76.

[16] APEX AMI Investigators, Armstrong PW, Granger CB, et al. Pexelizumab for acute ST-elevation myocardial infarction in patients undergoing primary percutaneous coronary intervention: a randomized controlled trial. JAMA 2007;297(1):43-51.

[17] National Cardiovascular Data Registry. 2013. https://cvquality.acc.org/NCDR-Home/registries.

[18] Duvernoy CS, Smith DE, Manohar P, et al. Gender differences in adverse outcomes after contemporary percutaneous coronary intervention: an analysis from the blue cross blue shield of michigan cardiovascular consortium (BMC2) percutaneous coronary intervention registry. American Heart Journal 2010;159(4):677-83.e1.

[19] Kralev S, Hennig O, Lang S, et al. Sex-based differences in clinical and angiographic outcomes in patients with ST-elevation myocardial infarction treated with concomitant use of glycoprotein IIb/IIIa inhibitors. Cardiology Journal 2010;17(6):580-6.

[20] Hannan EL, Racz MJ, Arani DT, et al. Short- and longterm mortality for patients undergoing primary angioplasty for acute myocardial infarction. J Am Coll Cardiol 2000;36(4):1194-201.

[21] De Luca G, Suryapranata H, Dambrink JH, et al. Sexrelated differences in outcome after ST-segment elevation myocardial infarction treated by primary angioplasty: data from the Zwolle myocardial infarction study. Am Heart J 2004;148(5):852-6.

[22] Cantor WJ, Miller JM, Hellkamp AS, et al. Role of target vessel size and body surface area on outcomes after percutaneous coronary interventions in women. Am Heart J 2002;144(2):297-302.

[23] Hirakawa Y, Yuichiro Masuda Y, Kuzuya M, et al. Impact of gender on in-hospital mortality of patients with acute myocardial infarction undergoing percutaneous coronary intervention: an evaluation of the TAMIS-II Data. The Japanese Society of Internal Medicine 2007;46(7):363-6. 